be found. On the other hand, an index of bed separation is defined and evaluated that correlates very well with the longitudinal variation of summer sliding velocity inferred for Variegated Glacier. This bed separation parameter is defined as

$$
I \equiv \tau / \mathcal{N}_{\mathrm{eff}}
$$

where $\tau$ is the basal shear stress and is proportional to the drop in normal stress on the downglacier side of bedrock bumps and $\mathcal{N}_{\text {eff }}$ is the effective normal stress equal to the overburden stress minus the subglacial water pressure. The water-pressure distribution is calculated assuming water flow to be confined in subglacial Röthlisberger conduits. The excellent agreement between the longitudinal profiles of $I$ and sliding velocity suggests that calculations of the variation of bed separation can be used to deduce the variation of sliding velocity in both space and time. Further, it is possible that a functional relationship can be developed that adequately represents the geometric controls on basal sliding to permit accurate predictions of sliding velocities.

\title{
REFERENCE
}

Meier, M. F. 1968. Calculations of slip of Nisqually Glacier on its bed: no simple relation of sliding velocity to shear stress. Union de Géodésie et Géophysique Internationale. Association Internationale d'Hydrologie Scientifique. Assemblée générale de Berne, 25 sept.-7 oct. 1967. [Commission de Neiges et Glaces.] Rapports et discussions, p. 49-57. (Publication No. 79 de l'Association Internationale d'Hydrologie Scientifique.)

\section{VARIATIONS IN TIME AND SPACE OF THE VELOCITY OF LOWER GOLUMBIA GLACIER, ALASKA}

\author{
By Mark F. Meier \\ (U.S. Geological Survey, Suite 850, i 20 I Pacific Avenue, Tacoma, Washington 98402, U.S.A.)
}

Abstract. Ice velocity, acceleration, and strain-rate are being measured at intervals of about $45 \mathrm{~d}$ using automated processing of aerial photographs. Preliminary results for the lowest $6 \mathrm{~km}$ of Columbia Glacier for the period July I 976 to November 1977 show the following:

( I) High rates of flow $(2-6 \mathrm{~m} / \mathrm{d}$ ) and longitudinal extension (occasionally exceeding $\mathrm{I} / \mathrm{a}$ ).

(2) A smooth, almost sinusoidal change in velocity $6 \mathrm{~km}$ above the terminus from about $2 \mathrm{~m} / \mathrm{d}$ in August 1976 and 1977 to about $3 \mathrm{~m} / \mathrm{d}$ in February-March 1977.

(3) Very rapid increases in velocity near the terminus in October 1976 and SeptemberOctober 1977 which follow embayment formation (increased iceberg calving).

(4) A suggestion that the rapid velocity increases propagate up-glacier for 3-4 $\mathrm{km}$ before becoming unrecognizable.

(5) Seasonal changes in velocity (which presumably relate to basal sliding) ranging from about $\mathrm{I} \mathrm{m} / \mathrm{d} 6 \mathrm{~km}$ above the terminus to about $4 \mathrm{~m} / \mathrm{d}$ near the terminus.

The rapid increase of velocity near the terminus appears to be caused by the transient increase in effective ice slope due to ice-cliff retreat. The high rate of basal sliding and the velocity peak in mid-winter imply unusual conditions at the bed. If one assumes that the basal water is in the form of a layer punctured by roughness elements (Weertman-Robin), calculation suggests a reversed generalized pressure gradient in this reach, resulting in water storage (unfortunately one cannot be sure of this because the basal shear-stress gradient is difficult to compute near the terminus). If one assumes that the basal water pressure is determined by a Röthlisberger conduit, the pressure in the conduit approaches, or perhaps even exceeds, the basal ice pressure. Thus an unusually thick water layer appears likely, but the seasonal variation remains to be explained. 